\title{
Visual Image Filtering at the Level of Cortical Input
}

\author{
Aleksandr BULATOV, Algis BERTULIS \\ Department of Biology, Kaunas University of Medicine \\ Mickevičiaus 9, LT-3000, Kaunas, Lithuania \\ e-mail:bulatov@vision.kmu.lt
}

Received: October 2004

\begin{abstract}
A computational model of the spatial-frequency filtering processes at the level of $4 \mathrm{C} \beta$ layer of the visual striate cortex is being proposed. The model does not interfere with the filtering performed by the cortical receptive fields itself, and the focus of attention is restricted to the cortical input. The model is based on the literature data concerning the conformal mapping of the visual field representation at the primary visual cortex and uniformity of short-range horizontal connections of cortical neurons. To test the model, the illusory figures were used as input stimuli, responses to which were computed and the output patterns constructed. The psychophysical experiments employing the same illusory figures were performed. A rather good correspondence between the model predictions and the experimental measurements of perceived size distortions was observed. In practice, the neurophysiological model provides a simplified and relatively fast algorithm of evaluation of distortions caused by filtering.
\end{abstract}

Key words: visual recognition, image filtering, primary visual cortex, perceived size distortions.

\section{Introduction}

The functional efficiency of the visual system is related to its ability to remove redundant information from the messages sent by the retina to the brain similar to such of computer compression software used to transmit large images along networks. Among the others, one remove is due to the filtering procedure performed in the visual pathways in relation to various parameters of an image. A parameter of that kind is the spatial frequency spectrum of the image. On their own turn, the filtering parameters depend considerably on the visual field representation in the primary visual cortex $\left(V_{1}\right)$ as well as on the lateral intracortical connections, also on density and distribution of the receptive fields of the cortical neurons.

Pioneering electrophysiological recordings of the cortex activity in primates (Daniel and Whitteridge, 1961; Talbot and Marshall, 1941) have established a topographic map of the visual field in $V_{1}$. The cortical representation of the central region of the visual field is relatively bigger than that of the peripheral part. Subsequent studies (Albus, 1975; Dow et al., 1981; Guld and Bertulis, 1976; Tootell et al., 1982; Tusa et al., 1978) of various biological subjects with application of metabolic markers, electro-sensitive stain- 
ing, positron-emission tomography, magnetic resonance imaging, various psychophysical procedures have set in order principles and details of topology of the primary visual cortex. Simultaneously, the experiments with microelectrode recordings of single units (Glezer et al., 1980; Hubel and Wiesel, 1968; 1974; 1977) have triggered an understanding of functional organization of cortical modules and various types of receptive fields.

The obtained experimental data on organization of the lower pathways of the visual system have stimulated the testing and modelling of striking visual experience and phenomena: geometrical illusions and hallucinations (Bressloff et al., 2001; Bulatov et al., 1997; Earle and Maskell, 1995; Ginsburg, 1979; Grüsser, 1995; Morgan and Casco, 1990; Schwartz, 1980). The numerous geometrical illusions, well-known and well-documented distortions of perception (Gregory, 1970), illustrate the seeing conditions in which discrepancies between visual perception and real images are permanent and reproducible. The geometric hallucinations are recognized as a dynamic and less static process, “... the instability of which reflects an instability in its conditions in origin" (Klüver, 1966). Together, the two phenomena serve both as indications of the seeing limits and as the appropriate tools for studies of the functional structure of the visual system. For instance, the experimental investigations on illusions and modelling approaches have provided evidence that spatial filtering processes unavoidably produce distortions in size and shape relations in various parts of an image in accordance with the uncertainty principle which defines a certain interrelation between the extent of a signal and its spectral characteristics. The magnitude of the perceptual distortions depends directly on the parameters of the filtering system (Ginsburg, 1979; Eijkman, 1981; Morgan, Casco, 1990; Earle, Maskell, 1995; Bulatov et al., 1997; 2001; Bulatov and Bertulis, 1999). The studies of geometric hallucinations like migraine phosphenes have helped in reckoning of quantitative characteristics of the topographic map of the visual field in $V_{1}$ (Grüsser, 1995; Schwartz, 1980). The investigations of illusions and hallucinations have been recognized as truly valid and convincing approaches (Klüver, 1966; Bressloff et al., 2001).

Accordingly, we have made an attempt to examine whether the lateral connections and the visual field representation in the layer $4 \mathrm{C} \beta$ of $V_{1}$ are directly related to the perceptual distortions of images. We have constructed a simplified model of functional structure of the $V_{1}$ input at the $4 \mathrm{C} \beta$ morphological layer. The model employed the neurophysiological data on the properties of the retino-cortical pathways, the principles of spatial organization of concentric cortical receptive fields, and the scheme of the lateral connections of the neurons in the cortex. To test our model, we used illusory figures as the input stimuli, in response to which the output signal patterns were computed. Psychophysical experiments employing the same illusions were performed as well. The model predictions and the experimental results were found in a rather good correspondence to one another, thereby illustrating the parameters of the spatial-frequency filtering of the images at the cortical input level.

\section{Neurophysiologhical Basis}

According to the literature data, the anatomy of the striate cortex may be specified as being homogeneous. Density of the cortical neurons, in contrast with that of the retinal 
ganglion cells, is practically the same overall the surface of the primary cortex (Hubel and Wiesel, 1974).

The weighting function of a simple receptive field may be approximated by the twodimensional Gabor function, which provides minimum uncertainty of mutual spatial- frequency and orientation selectivity. Due to this property of the simple receptive fields, the filtering optimum may be achieved in $4 \mathrm{C}$. Here, the vast number of neurons possesses the concentric and relatively small simple receptive fields. The outer and inner layers of the striate cortex comprise mainly large complex receptive fields.

Using microelectrodes to record single units, Hubel and Wiesel (1968) examined position of the receptive fields in the retina. They found the changes of the positions being negligible and accidental when small steps of the cortical displacement of the microelectrode were made in directions perpendicular or parallel to the cortical surface. Therefore, they concluded the presence of the Gaussian distribution of the centres of the real receptive fields in a given recording site and postulated the existence of the aggregate receptive field with mean size plus scatter. On the contrary, the cortical projection of the average receptive field plus scatter is equivalent to a cortical point image, the distribution of cortical neural activity resulting from a point of light on the retina (Dow et al., 1981). The point image size is about $10 \mathrm{~mm}$ in the foveal projection, but it varies with eccentricity. Irrespective of random distribution of local cortical interconnections, the primary visual cortex is organized in a systematic topographic map, i.e., adjacent retinal areas are projected on to adjacent cortical regions as it has been established by Talbot and Marshal (1941) and, subsequently, confirmed by Daniel and Whitteridge (1961).

The nonhomogeneity of the topographic map was termed (Daniel and Whitteridge, 1961) as the cortical magnification factor to describe the amount of cortical surface devoted to a given portion of visual space (Dow et al., 1981; Hubel and Wiesel, 1974). The ratio value decreases with eccentricity. In the foveal region of $V_{1}$, the magnification factor achieves a maximum of about $6 \mathrm{~mm} / \mathrm{deg}$, and in the far periphery region $\left(90^{\circ}\right)$ it reduces to $0.15 \mathrm{~mm} / \mathrm{deg}$. The magnification factor varies slightly from species to species in mammals, nevertheless, the hyperbolic function fits well with the experimental data average (Grüsser, 1995; Hubel and Wiesel, 1974; Schwartz, 1980).

The receptive field size growth observed with its displacement toward periphery indicates the visual system to have properties of the spatial-frequency filters with, substantially, nonhomogeneous parameters. The sizes of the cortical receptive fields are smaller in the fovea than that in the retinal periphery. The complex neurons in the cortical projection of the very centre of the fovea possess the receptive fields of about $0.25^{\circ} \times 0.5^{\circ}$ size while the majority of the neurons in the projections of the retinal periphery take up the receptive fields as big as $2^{\circ} \times 4^{\circ}$.

The local cortical interconnections are found as being relatively short. In both horizontal and oblique orientations, they do not exceed $2 \mathrm{~mm}$ length in most cases, and occasionally, achieve 4 to $5 \mathrm{~mm}$ size (Blasdel, 1992; Bosking et al., 1997; Budd and Kisvárday, 2001; Eysel, 1992, 1999). The vertical interconnections between the neurons of various layers are limited by the natural cortex boundaries. According to Hubel's and Wiesel's assumptions (Hubel and Wiesel, 1968; 1977), a segment of the cortex of $2 \times 2 \mathrm{~mm}$ size 
should carry a complete set of mechanisms of processing of information transmitted from a certain portion of the visual space. The hypothetical functional subunit of $2 \mathrm{~mm}$ size is a proper characteristic of the 3rd layer, though. In the 5th and 6th layers, the cortical subunits ought appear larger since the size and scatter of the receptive fields of the neurons are twice bigger. In the $4 \mathrm{C}$ layer, size and scatter of the receptive fields of the neurons are of much smaller extent than those, and the functional subunits might measure up to $0.2 \mathrm{~mm}$. In accordance with the most recent findings (Bosking et al., 1997; Eysel, $1992 ; 1999)$, the horizontal cortical connections which do not exceed $0.5 \mathrm{~mm}$ distance are to be considered isotropic and having a standard organization of excitatory centre and inhibitory surround. Consequently, an additional procedure of spatial filtering of images appears to be performed at the level of $4 \mathrm{C}$ layer of $V_{1}$.

\section{Modelling and Discussion}

Models of filtering processes at the cortical level face numerous neurophysiological factors of influence, such as nonhomogeneity of filtering parameters, weighting function shape variations, changes in the receptive field size and overlap degree. Yet, uniformity and short-range horizontal connections of the $4 \mathrm{C} \beta$ neurons may reduce some modelling expenditure, and therefore two assumptions might come forward.

The first assumption is concerned with the cortical magnification factor as a function of eccentricity. In the studies of the topographic map of the visual field in $V_{1}$ (Grüsser, 1995; Hubel and Wiesel, 1974; Letelier and Varela, 1984; Rovamo and Virsu, 1984; Schwartz, 1980), a linear characteristic of the inverse magnification factor,

$$
M^{-1}(\rho)=\frac{\rho+a}{k}
$$

is used, where $\rho$ is eccentricity, $k$ and $a$ are constants. Since the magnification factor is a derivative,

$$
M(\rho)=\frac{\mathrm{d} L}{\mathrm{~d} \rho},
$$

the distance on the cortex is determined by the following equation:

$$
L(\rho)=\int_{0}^{\rho} M(r) \mathrm{d} r=\int_{0}^{\rho} \frac{k \mathrm{~d} r}{r+a}=k \ln (\rho+a) .
$$

Supposing that the local magnification factor is isotropic, the topography of retinal representation on the cortex might be shown in a conformal transformation appearance,

$$
w(z)=k \cdot \ln (z+a)
$$


where $w(z)=u(z)+i v(z)$ is a vector in the cortex plane, and $z(x, y)=x+i y$ is a vector in the visual field plane. By means of simple calculations, the equations for the components of the cortical vector may be obtained:

$$
\begin{aligned}
& u(x, y)=k \cdot \ln \left(\sqrt{\left[\operatorname{arctg}\left(\frac{x}{D}\right)+a\right]^{2}+\operatorname{arctg}\left(\frac{y}{D}\right)^{2}}\right), \\
& v(x, y)=k \cdot \operatorname{arctg}\left(\frac{\operatorname{arctg}\left(\frac{y}{D}\right)}{\operatorname{arctg}\left(\frac{x}{D}\right)+a}\right),
\end{aligned}
$$

and the inverse relations for the components of the visual field vector as well:

$$
x(u, v)=D \operatorname{tg}\left(\mathrm{e}^{\frac{u}{k}} \cdot \cos \left(\frac{v}{k}\right)-a\right) \text { and } y(u, v)=D \operatorname{tg}\left(\mathrm{e}^{\frac{u}{k}} \cdot \sin \left(\frac{v}{k}\right)\right)
$$

where $D$ is a distance to the plane of an image.

The next assumption is related to the character of the horizontal links between the $4 \mathrm{C}$ neurons and the local centre-surround organizations, the linear dimensions of which do not exceed 0.1-0.2 mm (Aleksander et al., 1999; Bosking et al., 1997; Eysel, 1992, 1999). The functional properties of these organizations with an excitatory centre and inhibitory surround correspond to those of spatial-frequency filters, the weighting function of which is determined by the difference of the Gauss functions $D o G$ :

$$
D o G(u, v)=\exp \left(-\frac{\left(u^{2}+v^{2}\right)}{2 \sigma^{2}}\right)-A \exp \left(-\frac{\left(u^{2}+v^{2}\right)}{2(n \sigma)^{2}}\right),
$$

where $\sigma$ determines the size of the summation area of excitation; $A$ and $n$ are coefficients The condition,

$$
\int_{-\infty}^{+\infty} \int_{-\infty}^{+\infty} D o G(u, v) \mathrm{d} u \mathrm{~d} v=0 \text { indicates that } A \text { is equal to } n^{-2} .
$$

There were four main stages of image processing in the present modelling:

1. Formation of the input matrix $I$. The matrix $I$ corresponds to a grayscale BMP image with dimensions of $600 \times 600$ pixels. Simple images of polar and orthogonal grids have been selected to illustrate in an easy way the geometry changes caused by the conformal transformation.

2. Representation of the matrix $I$ onto the matrix $C$ in correspondence to the excitatory pattern by means of (5) (Fig. 2).

3. Convolution of the matrix $C$ with the matrix $F$, the elements of which are determined by the weighting function (7), and the size of which is the same as $C$ (Fig. 3).

4. Reconstruction of the matrix $I^{\prime}$ of the image by means of the inverse relations (6) from the matrix obtained by convolution in the previous step (Fig. 4). 


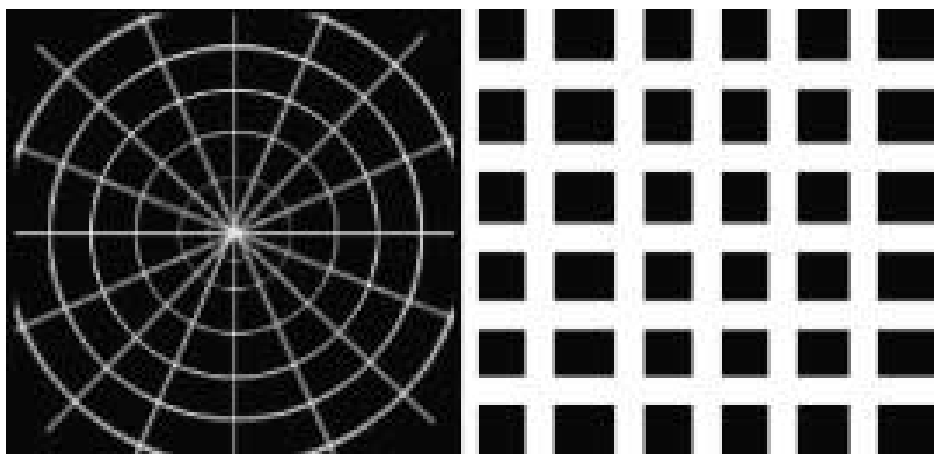

Fig. 1. Matrices $I$ of the input patterns.
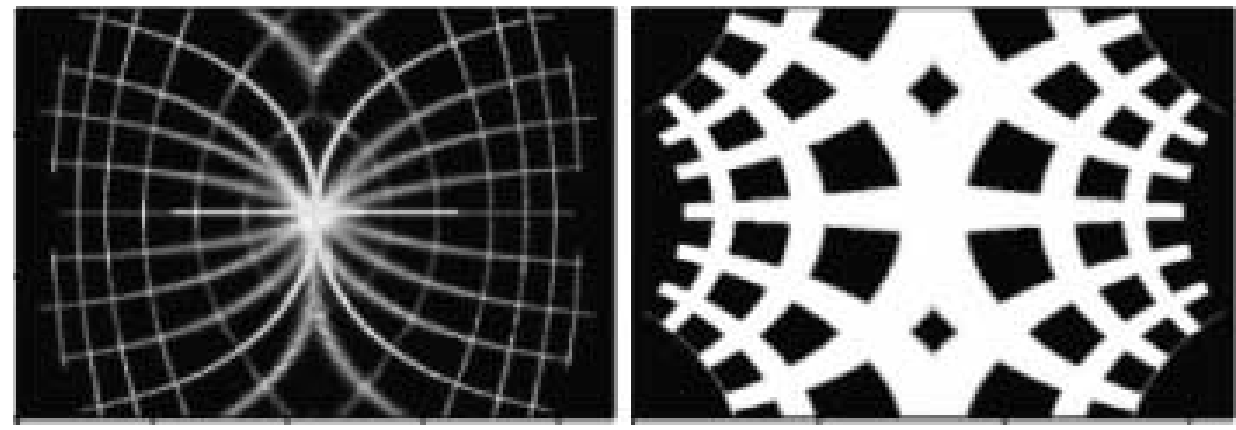

Fig. 2. Representation of matrices $I$ obtained by the conformal transformation (5).
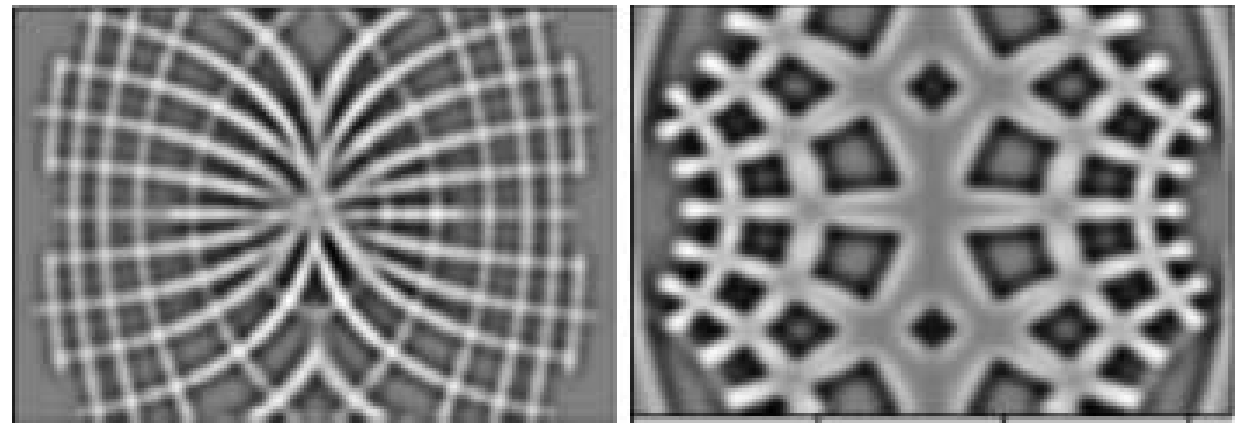

Fig. 3. Convolution of the matrices shown in Fig. 2 and a matrix the elements of which are determined by the filter weighting function (7).

Due to uniformity of short-range horizontal links in the $4 \mathrm{C} \beta$ of $V_{1}$, the filtering parameters (7) remain invariable overall the extent of the visual field. Nevertheless, the logarithmic character of the transformation (5) inflicts geometry of the image and, therefore, the parts of the image exposed in the central area of the visual field expand, and those in the periphery shrink. In other words, the resulting filtering does not remain homogeneous 


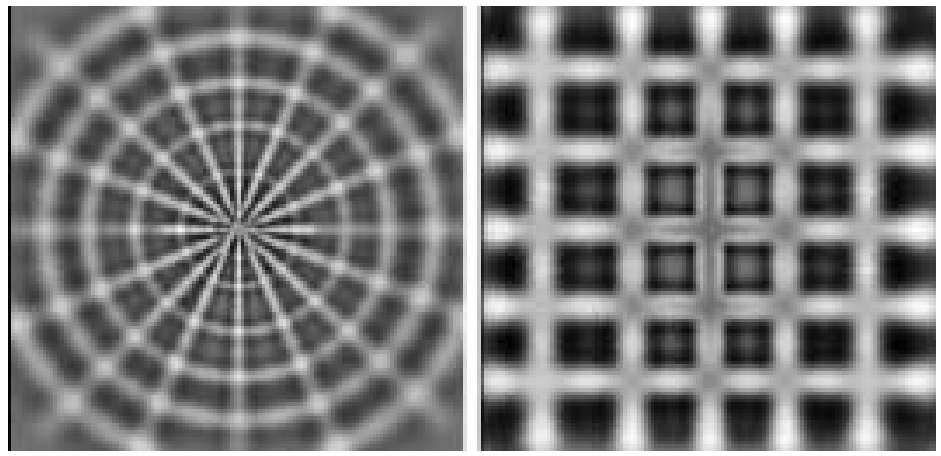

Fig. 4. The resulting patterns obtained from Fig. 3 matrices by the inverse transformations (6).

but increases with eccentricity. Together with eye movements and displacement of the gaze fixation point, the stimulus slides in various directions in accordance with the image matrix centre and hits the areas with various filtering parameters causing corresponding distortions (Fig. 4).

\section{Experimental Testing}

To test the model, psychophysical experiments were performed. The experiments were controlled by computer programs of our own design that arranged the order of the stimuli, presented them on the monitor, implemented alterations according to the subject's command, recorded the subject's responses, and computed the results. The experiments were carried out in a dark room and the display frame could not be discerned. The subjects viewed the stimuli monocularly through an artificial $3 \mathrm{~mm}$ pupil. The viewing distance was $400 \mathrm{~cm}$. A chin holder limited movements of the subject's head. To measure the perceived length distortions, the Müller-Lyer figure was generated against a dark background on the EIZO T562 monitor with gamma correction. For generation of the patterns, a Cambridge Research Systems VSG 2/3 was used. The stimuli patterns were oriented horizontally with the reference and test intervals arranged on the left and the right sides (Fig. 5A). In the experiments, the tilt angle of the wings of the Müller-Lyer figure varied from $10^{\circ}$ to $170^{\circ}$. The subjects estimated the perceived length of the test part of the figure and adjusted it to be equal in length with the reference one. No instructions concerning the gaze fixation point were given. In presentations, the subjects were asked to disregard the random changes in the reference value. The length of the test part of the figure was also randomized, and subjects did not know in advance whether the computer program would show it longer or shorter and how much different it might be from the length of the reference part. The errors of the subjects were considered as illusion strength values. A hundred and seventy-five presentations were included in a single experiment, i.e., 35 values of each parameter were repeated five times. The experiment was repeated two or three times during a session. 

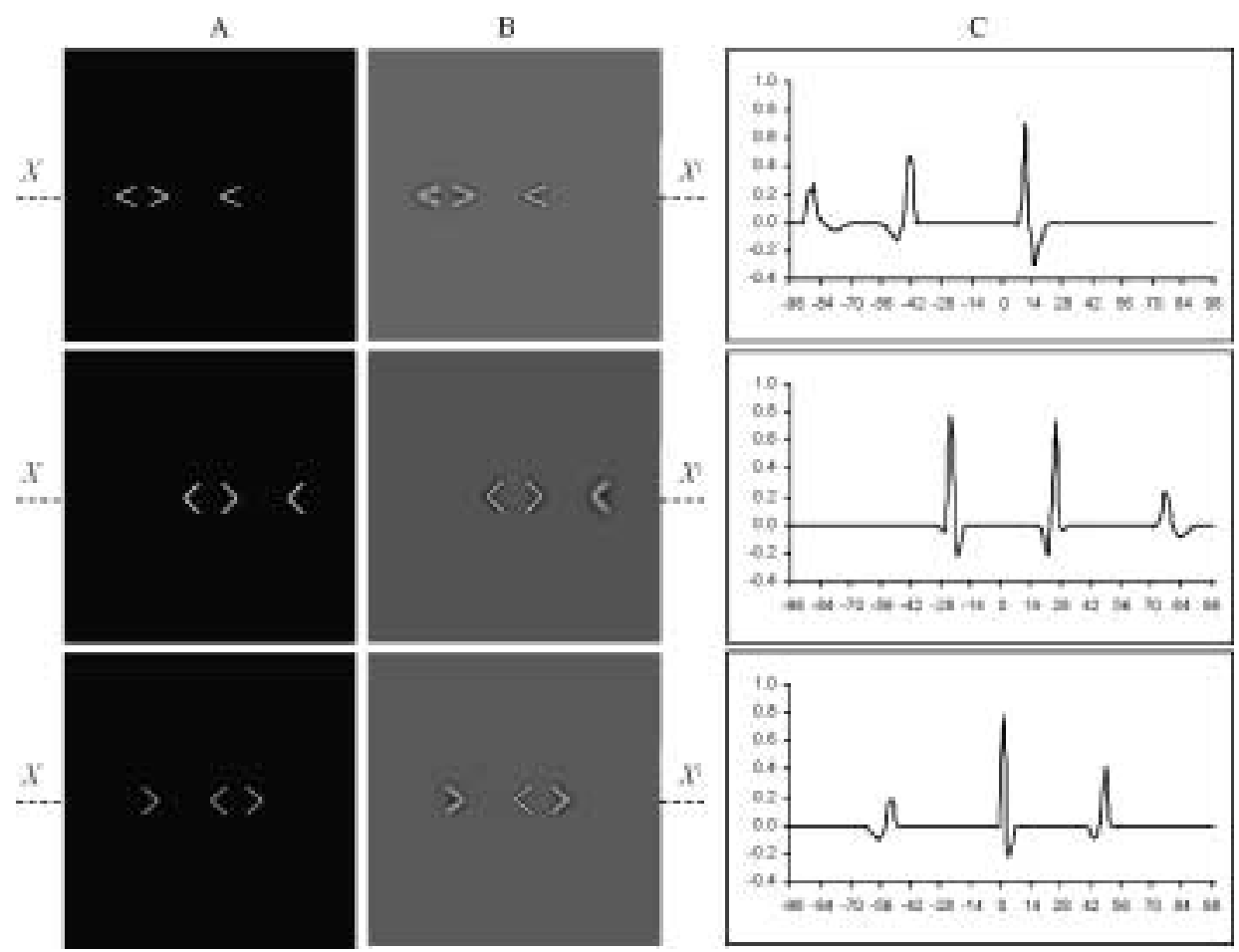

Fig. 5. The Müller-Lyer stimuli (A), and the output patterns of the model (B). The normalized transverse sections of the output patterns on the axis $X-X^{\mid}$illustrates the size relations of two parts of the patterns (C). The zero values on the abscissa axes indicate the gaze fixation points.

In Fig. 6, the measurements of the visual illusion function are shown together with the modelling curve. The modelling curve is obtained by estimating the size relations in the output patterns (Fig. 5B and C). The model parameters ( $a=1.083 ; k=15.57 ; \sigma=0.2)$ have been obtained from the averaged literature data, and the experimental results of two tested observers indicate well known individual variability of the pshychophysical measurements of the illusion. These individual differences can be explained by: (i) differences of filtering parameters of the visual systems of various subjects, (ii) eye movements with preference of gaze fixation position within a stimulus during the experimental procedure (Bulatov et al., 1997). Irrespective of the individual differences, the shape of the modelling curve resembles that of the experimental data, thereby illustrating the parameters of the spatial-frequency filtering of the images at the $4 \mathrm{C} \beta$ cortical level.

The present modelling approach is far from a complete picture of filtering procedures because of simplifications applied. Generally, the model is not related to the filtering performed by the cortical receptive fields per se. The latter processes have been tested separately (Bulatov et al., 1997). A comprehensive construction of the spatial image filtering in the visual pathways would be the next step in following studies. 


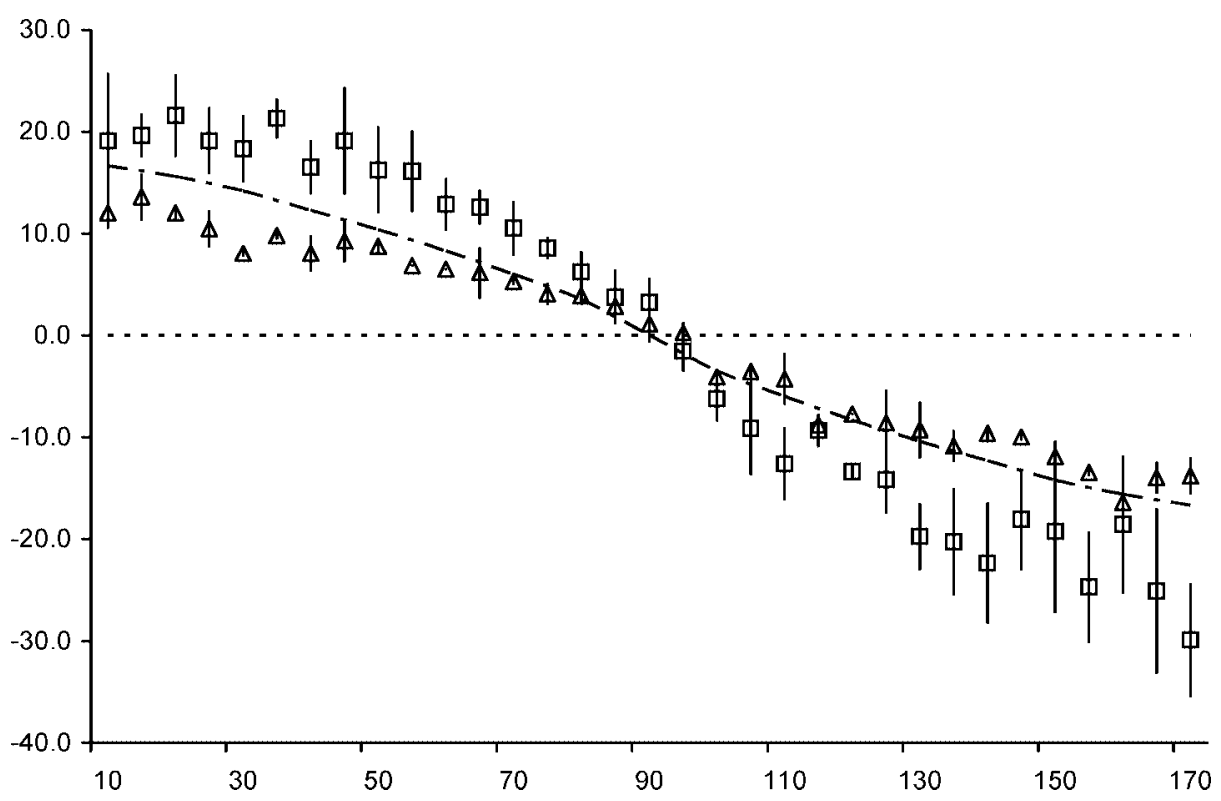

Fig. 6. The perceived length distortion as a function of the wing tilt angle for the subjects' UL (triangles) and NB (squares). The thin dashed line shows the predictions of the model.

\section{Conclusions}

1. The reported spatial filtering model has been developed basing on the literature data concerning with the principles of cortical representation of the visual field and properties of horizontal interconnections in the primary visual cortex.

2. The model quantitatively describes the spatial-frequency filtering parameters at the cortical input level.

3. A rather good correspondence between the model predictions and the psychophysical measurements of distortions of the perceived size was determined.

\section{References}

Aleksander, D.M., P. Sheridan, P. Bourke, O. Konstandatos and J.J. Wright (1999). Emergent symmetry of local and global maps in the primary visual cortex: Self-organization of orientation preference. Complexity International (Australia), 6, ISSN 1320-0682.

Albus, K. (1975). A quantitative study of the projection area of the central and paracentral visual field in area 17 of the cat. Exp Brain Res, 24, 159-179.

Blasdel, G.G. (1992). Orientation selectivity, preference, and continuity in monkey striate cortex. J Neuroscience, 12, 3139-3161.

Bosking, W.H., Y. Zhang, B. Schofield and D. Fitzpatrick (1997). Orientation selectivity and arrangement of horizontal connections in tree shrew striate cortex. J Neuroscience, 17, 2112-2127.

Bressloff, P.G., J.D. Cowan, M. Golubitsky, P.J. Thomas and M.C. Wiener (2001). Geometric visual hallucinations, Euclidean symmetry and the functional architecture of striate cortex. Philos Trans R Soc Lond B Biol Sci, 356(1407), 299-330. 
Budd, J.M.L., and Z.F. Kisvárday (2001). Local lateral connectivity of inhibitory clutch cells in layer 4 of cat visual cortex (area 17). Exp Brain Res, 140, 245-250.

Bulatov, A., and A. Bertulis (1999). Distortions of length perception. Biol Cybern, 80, 185-193.

Bulatov, A., A. Bertulis and L. Mickiene (1997). Geometrical illusions: study and modeling. Biol Cybern, 77, 305-407.

Bulatov, A., A. Bertulis and V. Strogonov (2001). Distortions of length perception in a combination of illusory patterns. Human Physiol, 27, 274-283.

Daniel, P.M., and D. Whitteridge (1961). The representation of the visual field in the cerebral cortex in monkeys. J Physiol (Lond), 159, 302-321.

Dow, B.M., A.Z. Snyder, R.G. Vautin and R. Bauer (1981). Magnification factor and receptive field size in foveal striate cortex of the monkey. Exp Brain Res, 44, 213-228.

Earle, D.C., and S.J. Maskell (1995). Spatial filtering and the Zöllner-Judd geometrical illusion: further studies. Perception, 24(12), 1397-1406.

Eysel, U.T. (1992). Lateral inhibitory interactions in area 17 and 18 of the cat visual cortex. Prog Brain Res, 90, 407-422.

Eysel, U. (1999). Turning a corner in vision research. Nature, 399, 641-644.

Ginsburg, A.P. (1979). Visual perception based on spatial filtering constrained by biological data. In Proceed. of the International Conference on Cybern. and Society (IEEE Cat. N. 79CH1424-1SMC).

Glezer, V.D., T.A. Tsherbach, V.E. Gauzelman and V.M. Bondarko (1980). Linear and non-linear properties of simple and complex receptive fields in area 17 of the cat visual cortex. A model of the field. Biol Cybern, 37(4), 195-208.

Gregory, R.L. (1970). The Intelligent Eye. Wiedenfeld and Nicolson, London.

Grüsser, O.J. (1995). Migraine phosphenes and the retino-cortical magnification factor. Vision Res, 35, 11251134.

Guld, C., and A. Bertulis (1976). Representation of fovea in the striate cortex of vervet monkey, Cercopithecus aethiops pygerythrus. Vision Res, 16, 629-631.

Hubel, D.H., and T.N. Wiesel (1968). Receptive fields and functional architecture of monkey striate cortex. $J$ Physiol (Lond), 195, 215-243.

Hubel, D.H. and T.N. Wiesel (1974). Uniformity of monkey striate cortex. A parallel relationship between field size, scatter, and magnification factor. J Comp Neurol, 158, 295-306.

Hubel, D.H., and T.N. Wiesel (1977). Functional architecture of macaque monkey visual cortex. Proc $R$ Soc Lond [Biol], 198, 1-59.

Klüver, H. (1966). Mescal and Mechanisms and Hallucinations. University of Chicago Press.

Letelier, J.C., and F. Varela (1984). Why the cortical magnification factor in rhesus is isotropic? Vision Res, 24, 1091-1095.

Morgan, M.J., and C. Casco (1990). Spatial filtering and spatial primitives in early vision: An explanation of the Zöllner-Judd class of geometrical illusion. Proc R Soc London [Biol], 242(1303), 1-10.

Rovamo, J., and V. Virsu (1984). Isotropy of cortical magnification and topography of striate cortex. Vision Res, 24, 283-286.

Schwartz, L. (1980). Computational anatomy and functional architecture of striate cortex: a spatial mapping approach to perceptual coding. Vision Res, 20, 645-669.

Talbot, S.A., and W.H. Marshall (1941). Physiological studies on neural mechanisms of visual localization and discrimination. Am J Ophthalmol, 24, 1255-1263.

Tootell, R.B.H., M.S. Silverman, E. Switkes and R.L. DeValois (1982). Desoxyglucose analysis of retinotopic organization in primate striate cortex. Science, 218, 902-904.

Tusa, R.J., L.A. Palmer and A.C. Rosenquist (1978). The retinotopic organization of area 17 (striate cortex) in the cat. J Comp Neurol, 177, 213-236. 
A. Bulatov is a university lecturer, D. Sc. at Kaunas University of Medicine. His research interests include visual recognition, distortions of perception, modelling of the sensory information processing in the neural networks.

A. Bertulis, professor of biology, MD. D. Sc. habil is a head of Department of Biology at Kaunas University of Medicine. His research interests include visual recognition, distortions of perceived image size and shape, colour vision, neurophysiology of the retina and primary visual cortex. In 1991, he became the organizer of the XIV European Conference on Visual Perception held in Lithuania. In 1994, became a winner of the National Award on Science. 


\section{Vaizdo filtracija regos pirminès žievès lygyje}

\section{Aleksandr BULATOV, Algis BERTULIS}

Pasiūlytas matematinis erdvinès-dažninès filtracijos, vykstančios regos pirminès žievès $4 \mathrm{C} \beta$ morfologinio sluoksnio lygyje, modelis. I modelio struktūra neitrauktos neuronu recepcijos lauku savybès, ir dèmesys koncentruojamas ties žievès neuronu sluoksniu, i kuri ateina signalai iš žemesniuju regos centrų. Naudojami literatūriniai duomenys apie regos lauko projekcijos regos žievejje konforminę transformaciją ir žievès neuronų horizontalių trumpujų ryšių vienodumą. Modeliui patikrinti panaudoti geometrines iliuzijas sukeliantys stimulai. Tie patys stimulai naudojami psichofizikiniuose eksperimentuose, ir gauti duomenys lyginami su modelio skaičiavimais. Žmogaus suvokimo deformacijų ir modelio apskaičiuotu pakitimu charakteristikos yra artimai panašios. Modelis leidžia paprastai ir greitai apskaičiuoti filtracijos įnešamas deformacijas. 